\title{
Assessment of auditory function and lipid levels in patients receiving oral isotretinoin (13-cis retinoid) therapy for acne vulgaris
}

\author{
Mahizer Yaldiz ${ }^{1}$, Ahmet Kara², Mehmet Güven², Berna Solak ${ }^{1}$, Rabia Kara' ${ }^{1}$, Mustafa Teoman Erdem ${ }^{1}$ \\ 1Department of Dermatology, Training and Research Hospital, Sakarya University, Sakarya, Turkey \\ 2Department of Otorhinolaryngology, Training and Research Hospital, Sakarya University, Sakarya, Turkey
}

Adv Dermatol Allergol 2020; XXXVII (3): 360-363 DOI: ttps://doi.org/10.5114/ada.2018.79566

\begin{abstract}
Introduction: Isotretinoin (13-cis retinoid) is a synthetic retinoid. It was approved by the FDA in 1982 for use of oral isotretinoin in severe acne. It is also used in moderate-severe acne that does not respond to conventional treatments. Isotretinoin is the only available drug that affects all stages of acne pathogenesis.

Aim: To prospectively investigate whether there is an effect of isotretinoin therapy on auditory function and, if so, to demonstrate its association with simultaneous blood lipid levels.

Material and methods: Thirty patients (60 ears) with acne vulgaris, who received $0.5 \mathrm{mg} / \mathrm{kg}$ of isotretinoin therapy, were included in the study. Distortion product otoacoustic emissions (DPOAEs) and pure tone audiometry tests were performed to evaluate auditory function at the beginning of the procedure and the $6^{\text {th }}$ month of treatment. In addition, aspartate aminotransferase (AST), alanine aminotransferase (ALT), total cholesterol, triglyceride, high-density lipoproteins (HDL) and low-density lipoproteins (LDL) cholesterol levels were recorded.

Results: There was no statistically significant difference between pre-treatment and post-treatment mean pure tone audiometry threshold and DPOAE values; however, the increase in total blood cholesterol, triglyceride and LDL levels and the decrease in HDL levels were statistically significant.

Conclusions: According to our study findings, isotretinoin did not cause worsening of the bilateral hearing threshold, but increased blood lipid levels. There is no need for follow-up auditory functions in routine practice during therapy, but blood lipid levels should be monitored.
\end{abstract}

Key words: auditory function, acne vulgaris, isotretinoin.

\section{Introduction}

Isotretinoin (13-cis retinoid) is a synthetic retinoid. It was approved by the Food and Drug Administration (FDA) in 1982 for use of oral isotretinoin in severe acne. It is also used in moderate-severe acne that does not respond to conventional treatments. Isotretinoin is the only available drug that affects all stages of acne pathogenesis. Although isotretinoin is effective and generally well tolerated, it has a wide side effect profile. Like other retinoids, isotretinoin has side effects on the mucosa, skin, eye, liver, bone and musculoskeletal system $[1,2]$. Most of the common side effects rarely require cessation of treatment, and will recover spontaneously shortly after the treatment is terminated [1]. Side ef- fects of isotretinoin are well known, but ototoxicity is rarely reported, and its mechanism is not clear [1].

There have recently been reports of adverse effects of hyperlipidemia on auditory function [3, 4]. In addition, Boztepe et al. found a decrease in the pure tone audiometry thresholds at the $6^{\text {th }}$ month of isotretinoin therapy, and this finding was associated with an increase in triglyceride and total cholesterol levels [5].

\section{Aim}

The purpose of this prospective study is to investigate the effect of oral isotretinoin therapy on auditory function using pure tone audiometry (PTA) and distortion

Address for correspondence: Mahizer Yaldiz, Department of Dermatology, Sakarya Training and Research Hospital, Sakarya, Turkey, phone: +90 02642750090-1460, +90 05053572222, e-mail: drcanyaldiz@yahoo.com

Received: 24.10.2018, accepted: 28.10.2018. 
product otoacoustic emission (DPOAE) tests, and to show its association with simultaneous blood lipid levels.

\section{Material and methods}

The study group consisted of 30 (60 ears) patients selected from men or non-pregnant women with severe acne. Women with reproductive potential used at least two contraceptive methods and had a negative pregnancy test result 1 week prior to treatment. Isotretinoin therapy $(0.5 \mathrm{~g} / \mathrm{kg})$ was initiated and continued until reaching cumulative doses of $120 \mathrm{mg} / \mathrm{kg}$.

Before assessing the auditory functions of patients, detailed anamnesis was obtained from all patients and patients having the following criteria were excluded from the study: ototoxic drug use, exposure to noise, history of otologic surgery, Meniere's disease, cranial trauma, metabolic disease, autoimmune disease, allergy or susceptibility to paraben, being younger than 18 years and older than 35 years. Additionally, patients with acute or chronic otitis media findings on otoscopic examination were not included in the study. All audiologic evaluations were performed at the beginning of the treatment and at the end of the $6^{\text {th }}$ month using DPOAE and PTA tests for each patient and every measurement. In addition, aspartate aminotransferase (AST), alanine aminotransferase (ALT), total cholesterol, triglyceride, high-density lipoprotein (HDL) and low-density lipoprotein (LDL) cholesterol levels were measured at the beginning of the treatment and in monthly assessments. Local ethics committee approval was obtained before the study (SUEK.16214662/05001.04/100).

\section{Audiological evaluations}

The DPOAE tests were performed using a Madsen Capella Distortion Product Otoacoustic Emission System (Madsen Capella, Taastrup, Denmark) in the standard default mode. With this technique, a wide frequency range of the cochlea can be evaluated by providing two different sound stimuli termed F1 and F2 to the external ear channel to obtain a frequency-specific response from the cochlea. High frequencies are more likely to suffer from

Table 1. Pure audiometry test results evaluated before and after treatment

\begin{tabular}{lccc}
\hline Value & $\begin{array}{c}\text { First } \\
\text { measurement }\end{array}$ & $\begin{array}{c}\text { Second } \\
\text { measurement }\end{array}$ & $P$-value \\
\hline $500 \mathrm{~Hz}$ & $8.0 \pm 5.2$ & $7.0 \pm 6.1$ & 0.041 \\
\hline $1000 \mathrm{~Hz}$ & $6.1 \pm 4.6$ & $6.2 \pm 4.0$ & 0.853 \\
\hline $2000 \mathrm{~Hz}$ & $4.9 \pm 4.7$ & $4.4 \pm 3.8$ & 0.356 \\
\hline $4000 \mathrm{~Hz}$ & $6.1 \pm 5.7$ & $6.0 \pm 5.1$ & 0.736 \\
\hline $8000 \mathrm{~Hz}$ & $7.2 \pm 6.6$ & $7.6 \pm 7.9$ & 0.812 \\
\hline Mean & $6.5 \pm 3.6$ & $6.2 \pm 3.5$ & 0.546 \\
\hline
\end{tabular}

ototoxicity. In the current study, we studied both low and high frequencies $(0.75-8 \mathrm{kHz})$.

Pure tone audiological tests were performed with an AC 40 clinical audiometer (Inter acoustics, Assens, Denmark). The audiometer was calibrated according to the ISO standards. Hearing thresholds were determined in the range $0.5-8 \mathrm{kHz}$. Contralateral masking was carried out during measurements.

\section{Statistical analysis}

Statistical analysis was performed using IBM SPSS Statistics version 20.0 for Windows statistical software (IBM Corporation, Armonk, New York, USA). Continuous variables were expressed as mean \pm standard deviation. For distribution normality analyses, Kolmogorov-Smirnov analysis was performed, and non-parametric tests were preferred according to the results of this analysis. The Wilcoxon test was used for the comparisons. P-values less than 0.05 were accepted as significant.

\section{Results}

Forty patients were included in the study. Of these patients, 10 were excluded due to incomplete follow-up and 30 completed the study. Six of patients were male and 24 were female. Mean age of patients was $20.5 \pm 2.7$ years. There was no serious side effect due to use of oral isotretinoin. Audiologic complaints (hearing reduction, hearing loss, tinnitus, etc.) were not observed in any of the cases. The otoscopic examination of all participants before and after the procedure was normal. Air conduction hearing thresholds were considered as there were no differences in the air and bone conduction thresholds between the patients. Mean PTA value was $6.5 \pm 3.6$ before the treatment and it was $6.2 \pm 3.5$ after the treatment. When the specific mean values of the frequencies were evaluated, it was found that only the difference in the frequency of $500 \mathrm{~Hz}$ was statistically significant. No significant differences were observed between other frequencies. The data for the PTA measurements are presented in Table 1. No statistically significant difference was observed at any frequency or mean value for the

Table 2. DPOAE test results evaluated before and after treatment

\begin{tabular}{lccc}
\hline Value & $\begin{array}{c}\text { First } \\
\text { measurement }\end{array}$ & $\begin{array}{c}\text { Second } \\
\text { measurement }\end{array}$ & $P$-value \\
\hline $750 \mathrm{~Hz}$ & $5.1 \pm 4.1$ & $4.8 \pm 3.9$ & 0.881 \\
\hline $1000 \mathrm{~Hz}$ & $9.1 \pm 5.1$ & $8.5 \pm 5.8$ & 0.331 \\
\hline $2000 \mathrm{~Hz}$ & $10.3 \pm 4.3$ & $10.3 \pm 4.7$ & 0.805 \\
\hline $4000 \mathrm{~Hz}$ & $15.2 \pm 5.6$ & $15.6 \pm 5.6$ & 0.639 \\
\hline $8000 \mathrm{~Hz}$ & $15.5 \pm 7.8$ & $15.7 \pm 7.9$ & 0.958 \\
\hline Mean & $11.0 \pm 3.4$ & $11.0 \pm 3.4$ & 0.827 \\
\hline
\end{tabular}


Table 3. Biochemical test results evaluated before and after treatment

\begin{tabular}{lccc}
\hline Parameter & $\begin{array}{c}\text { First } \\
\text { measurement }\end{array}$ & $\begin{array}{c}\text { Second } \\
\text { measurement }\end{array}$ & P-value \\
\hline ALT & $15.8 \pm 7.5$ & $13.4 \pm 4.7$ & 0.02 \\
\hline AST & $16.7 \pm 4.4$ & $18.2 \pm 3.6$ & 0.01 \\
\hline $\begin{array}{l}\text { Total } \\
\text { cholesterol }\end{array}$ & $159.9 \pm 25.2$ & $175.4 \pm 27.8$ & $<0.001$ \\
\hline Triglycerides & $77.1 \pm 29.8$ & $108.9 \pm 51.5$ & $<0.001$ \\
\hline HDL & $50.2 \pm 9.9$ & $48.0 \pm 9.1$ & $<0.02$ \\
\hline LDL & $87.3 \pm 19.0$ & $103.3 \pm 25.5$ & $<0.001$ \\
\hline
\end{tabular}

DPOAE test, which was a frequency-specific otoacoustic emission test. The results are summarized in Table 2 .

Although isotretinoin therapy had a statistically significant effect on the liver when tested with AST and ALT values, it resulted in decreased ALT levels and increased AST levels. Significant increases in total cholesterol, triglyceride and LDL levels and a decrease in HDL levels proved its negative effect on blood lipid profile. The results of the biochemical test are summarized in Table 3.

Since there was no statistically significant deterioration in the hearing threshold values of volunteers included in the study, the association between changes in the blood lipid level and hearing impairment was not statistically evaluated.

\section{Discussion}

In this study, we did not find a statistically significant difference between mean pure tone audiometry threshold values and DPOAE with isotretinoin treatment, but we detected a statistically significant increase in total blood cholesterol, triglyceride and LDL levels and a decrease in HDL level.

Isotretinoin is a retinoid derivative used for acne treatment. Retinoids are natural or synthetic analogs of vitamin A, and modulate cellular growth, differentiation and immunomodulatory functions [1, 2]. Retinoic acid is also an endogenous signaling molecule, which can also play an important role during different phases of inner ear development [6]. Retinoic acid can affect several genes associated with mesenchymal epithelial interaction. Thus, it controls the morphogenesis of the inner ear $[7,8]$. Romand reported that retinoic acid signaling was critical not only for embryogenic development but also for postnatal preservation of the inner ear [8]. Isotretinoin has many common and uncommon side effects [1]. Side effects of isotretinoin are well known, but ototoxic side effects are rarely reported, and their mechanism is not clear. Ototoxic side effects range from relatively benign, such as tinnitus, to more serious, such as sensorineural hearing loss [9].
There are also opposite views. In some studies, retinoic acid was found to be a treatment option for hearing loss due to recurrent otitis media and noise exposure $[10,11]$. Lefebvre et al. reported that retinoic acid stimulated the regeneration of auditory hair cells after ototoxic drug-induced damage in rats [12]. The main mechanism of retinoic acid in the treatment of hearing loss involves its anti-inflammatory and anti-oxidant features. Moreover, the effect of retinoic acid in the regulation of connexin (Cx) expression, which is essential for normal hearing, is well known $[10,13]$. Our findings showed that isotretinoin therapy at a $0.5 \mathrm{mg} / \mathrm{kg}$ dose did not affect hearing thresholds.

There is a limited number of studies regarding the effects of isotretinoin on hearing. Aydogan et al. observed a significant increase in brain stem auditory evoked potentials of 32 patients receiving isotretinoin therapy [14]. Nikiforidis et al. investigated the auditory brain stem response in 33 acne vulgaris patients using isotretinoin, before and at the $3^{\text {rd }}$ week of treatment, and they found subclinical changes after treatment in 3 patients, although not statistically significant [15]. Ugur et al. reported that the use of isotretinoin in acne vulgaris patients may alter the bilateral hearing thresholds, although there was no significant change in the DPOAE and TEOAE amplitude levels [16]. Akdağ et al. determined a significant increase in mean hearing threshold values (except for $250-500 \mathrm{MHz}$ frequency) of patients using isotretinoin but found no significant difference in the signalto-noise ratio of TEOAE before and after treatment [17]. Karabulut et al. reported improvement in hearing levels of patients with acne vulgaris at all audiometric frequencies in the short-term follow-up period [18]. In our study, we found that changes in pure tone audiometry results at all frequencies except $500 \mathrm{~Hz}$ and the differences for all frequencies and mean values for the DPOAE test did not show a statistically significant result. The contradiction between the study results might be due to the small size of the study population, the absence of hearing loss in all study populations and using different methods for assessment of hearing function.

There are recent studies regarding the negative impact of hyperlipidemia on hearing. There are also publications reporting that a low cholesterol diet and antihyperlipidemic treatment improve sudden hearing loss [3, 4, 19, 20]. In the study of Boztepe et al. [5] conducted with patients with acne vulgaris, it was found that isotretinoin therapy influenced hearing, and triglyceride and cholesterol levels, and that increased blood lipid levels were associated with hearing impairment. The authors concluded that these two effects might occur due to the indirect consequence of a concurrent side effect of the drug and elevated blood lipid levels [5].

In our study, we found a statistically significant increase in total blood cholesterol, triglyceride and LDL levels and a decrease in HDL levels with the treatment 
of isotretinoin. These results were consistent with the literature [2, 21]. However, since there was no statistically analyzed impairment in the hearing thresholds of the volunteers included in the study, the association between changes in the blood lipid level and hearing impairment was not statistically analyzed.

The PTA, auditory evoked potentials and otoacoustic emissions were used in most of the studies on isotretinoin and hearing. Changes reported in the hearing thresholds in these studies, including our study, were not clinically significant, and most changes were determined by a subjective test, pure tone audiometry measurement. In addition, all the studies were small-scale. The contradiction between our findings and the results of other studies can be explained by these reasons.

\section{Conclusions}

According to our study results, we concluded that isotretinoin did not cause worsening of the hearing thresholds, but increased blood lipid levels. We believe that there is no need to follow up hearing functions in routine practice during the treatment period; however, blood lipid levels should be monitored. Due to the contradiction between studies on the effects of isotretinoin in the literature about hearing, there is a need to measure hearing function and verify this information with human and animal studies by means of large-scale and objective methods.

\section{Conflict of interest}

The authors declare no conflict of interest.

\section{References}

1. Brelsford M, Beute TC. Preventing and managing the side effects of isotretinoin. Semin Cutan Med Surg 2008; 27: 197-206.

2. Charakida A, Mouser PE, Chu AC. Safety and side effects of the acne drug, oral isotretinoin. Expert Opin Drug Saf 2004; 3: 119-29.

3. Karlidağ T, Açik Y, Kaygusuz I. The effect of hyperlipidemia on hearing function. Kulak Burun Bogaz Ihtis Derg 2002; 9: 112-6.

4. Thakur JS, Mohindroo NK, Vasanthalakshmi MS, et al. Auditory brainstem evoked responses in hyperlipidaemia: effect of various lipid fractions on auditory function. J Laryngol Otol 2012; 126: 249-56.

5. Boztepe OF, Alan S, Gün T, et al. Hearing loss in patients using isotretinoin: is it a side effect or due to hyperlipidemia? J Med Updates 2013; 3: 82-6.

6. Romand R, Dollé P, Hashino E. Retinoid signaling in inner ear development. J Neurobiol 2006; 66: 687-704.

7. Romand R, Kondo T, Cammas L, et al. Dynamic expression of the retinoic acidsynthesizing enzyme retinol dehydrogenase 10 ( $r d h 10)$ in the developing mouse brain and sensory organs. J Comp Neurol 2008; 508: 879-92.

8. Romand R. The roles of retinoic acid during inner ear development. Curr Top Dev Biol 2003; 57: 261-91.
9. Bigby M, Stern RS. Adverse reactions to isotretinoin. A report from the Adverse Drug Reaction Reporting System. J Am Acad Dermatol 1988; 18: 543-52.

10. Schmitz J, West KP, Khatry SK, et al. Vitamin A supplementation in preschool children and risk of hearing loss as adolescents and young adults in rural Nepal: randomised trial cohort follow-up study. BMJ 2012; 344: d7962.

11. Shim HJ, Kang HH, Ahn JH, et al. Retinoic acid applied after noise exposure can recover the noise-induced hearing loss in mice. Acta Otolaryngol 2009; 129: 233-8.

12. Lefebvre PP, Malgrange B, Staecker $\mathrm{H}$, et al. Retinoic acid stimulates regeneration of mammalian auditory hair cells. Science 1993; 260: 692-5.

13. Kim Y, Lin X. Effects of retinoid treatment on cochlear development, connexin expression and hearing thresholds in mice. J Otorhinolaryngol Hear Balance Med 2018; 1: 2.

14. Aydogan K, Turan OF, Onart S, et al. Neurological and neurophysiological effects of oral isotretinoin: a prospective investigation using auditory and visual evoked potentials. Eur J Dermatol 2008; 18: 642-6.

15. Nikiforidis G, Tsambaos D, Karamitsos D, et al. Effects of oral isotretinoin on human auditory brainstem response. Dermatology 1994; 189: 62-4.

16. Ugur KS, Erpolat S, Kurtaran H, et al. The effects of oral isotretinoin (13-cis retinoic acid) on the inner ear: a clinical study. Int Adv Otol 2012; 8: 339-44.

17. Akdağ M, Akkurt ZM, Gül A, et al. The effects of oral isotretinoin (13-cis retinoic acid) on the inner ear: a prospective clinical study. Clin Invest Med 2014; 37: E102-7.

18. Karabulut H, Karadag AS, Acar B, et al. The effect of oral isotretinoin (13-cis retinoic acid) on hearing systems in patients with acne vulgaris: a prospective study. Int I Dermatol 2011; 50: 1139-43.

19. Kojima Y, Ito S, Furuya N. Hearing improvement after therapy for hyperlipidemia in patients with chronic-phase sudden deafness. Ann Otol Rhinol Laryngol 2001; 110: 105-8.

20. Sutbas A, Yetiser S, Satar B, et al. Low-cholesterol diet and antilipid therapy in managing tinnitus and hearing loss in patients with noise-induced hearing loss and hyperlipidemia. Int Tinnitus J 2007; 13: 143-9.

21. Charakida A, Mouser PE, Chu AC. Safety and side effects of the acne drug, oral isotretinoin. Expert Opin Drug Saf 2004; 3: 119-29. 